\title{
DA SALA À CIDADE: AULAS DE ARQUEOLOGIA HISTÓRICA NO CENTRO DE TERESINA
}

\author{
Fabrícia de Oliveira Santos ${ }^{1}$
}

\section{Introdução}

As diversas paisagens das cidades comportam meios de acesso à sua essência: marcas de ocupação, metamorfoseadas em diversos suportes materiais e imateriais, definidas por uma lógica de produção do espaço que decreta ausências e permanências de memórias e de histórias, e fixam as imagens que representam as cidades. O acesso a essas marcas pode ser como um labirinto, ou um complicado "jogo de espelhos" (Ginzburg, 2001: 85) composto por ruas, becos, praças, monumentos, andarilhos, moradores fixos, construções as mais diversas, imagens como espelhos que podem revelar ou confundir o que é cada cidade.

Um exame inicial na historiografia piauiense, a fim de constituir material para aulas na disciplina de Arqueologia Histórica ${ }^{2}$, perquiriu referências culturais que pudessem ser examinadas como possibilidades de pesquisa para a Arqueologia Histórica no Piauí. Do levantamento preliminar, duas temáticas em destaque: a ocupação territorial do Piauí com a prática econômica da pecuária, e a produção da cidade de Teresina $^{3}$ como a nova capital no século XIX.

Foi explorada a segunda temática sobre a formação de Teresina, sua área central, projetada a partir da segunda metade do século XIX, que desvelou algumas marcas de sua formação territorial. Entre elas, duas praças - a Bandeira e a da Saraiva - que sobressaíram na historiografia, e na paisagem urbana teresinense. Praças que figuram como dois palimpsestos significativos para a leitura do tempo e da produção da cultura material e imaterial sobre a cidade.

\footnotetext{
${ }^{1}$ Universidade Federal de Sergipe, Brasil.

${ }^{2}$ A pesquisa foi realizada enquanto Professora do Bacharelado em Arqueologia e Conservação de Arte Rupestre da Universidade Federal do Piauí.

3 Por questões de logística - disponibilidade de transporte de discentes - esses dois temas foram explorados, respectivamente, como projeto de iniciação científica voluntária (Santos, 2011b), e material de aula (Santos, 2010; 2011a) para a referida disciplina.
} 
São praças com resquícios de traçados de um período imperial e republicano, quiçá colonial", com seus "tempos de espera" (Vidal, 2010) diferenciados na configuração da cidade. Para Vidal, esses "tempos" são caracterizados por duplas vertentes, uma administrativa, outra social, aplicadas às sociedades do período colonial, que, no tempo de espera das diversas determinações da metrópole "surgiam experiências políticas e sociais originais, às vezes bem diferentes do que a metrópole queria impor" (Vidal, 2010: 54).

Teresina, e, provavelmente, outras cidades brasileiras, ainda tem seus locais marcados por tempos de espera, não mais à espera da metrópole, mas da espacialização do capitalismo, tempos que deixam marcas singulares em suas paisagens. Tempos e condições materiais e imateriais desiguais, ordenamentos desiguais que imprimem configurações próprias aos cenários urbanos, de maneira que as praças examinadas, consideradas entre as mais antigas da cidade, agregam esses tempos e singularidades. Como observa Silva (2010: 18): “as praças são documentos materializados na paisagem urbana, testemunhando épocas pretéritas, sinalizando a história da cidade”. Documentos a serem lidos, interpretados. E, para a Arqueologia Histórica, as praças podem ser consideradas como artefatos, como elementos elaborados e modificados pela ação humana em um passado considerado recente, no caso das Américas, que tem por balizas temporais os momentos posteriores à expansão europeia neste continente (Orser, 2000).

A princípio, as praças foram visitadas como fonte possível para pesquisa arqueológica na área urbana de Teresina. Interpretações iniciais para um entendimento de sua formação territorial. As aulas nessas praças foram guiadas por questões sob um escopo teórico de compreendê-las como parte da produção do espaço teresinense sob a lógica do desenvolvimento desigual da economia capitalista (Smith, 1984). Processo que termina por segregar espaços em detrimento de outros e gerar distanciamentos, conforme o processo de valorização do espaço de cada tempo histórico e as demandas do sistema. Todavia, em choque com os distanciamentos, as resistências, conscientes ou não, também são verificadas, principalmente entre a permanência das praças em questão no cenário da cidade, garantidas por quem considera a suas existências como fator essencial à memória, à história, por quem tece uma imagem urbana para Teresina, imagem que Ferrara (1990) denomina de máscaras da cidade, que significam o

\footnotetext{
${ }^{4}$ Sobre as configurações para as praças, e a lógica definida para a área central de Teresina, alguns autores consideram influências europeias dos setecentos, sobretudo de países ibéricos (Braz e Silva, 2012; Silva Filho, 2007).
} 
conjunto de valores, hábitos, desejos e crenças que nutriam [nutrem], através dos tempos o cotidiano de seus habitantes.

\section{As praças, sua (in)visibilidade na paisagem de Teresina - além das máscaras}

Entre as imagens das praças, uma questão inicial: duas praças - dois territórios, com controles e relações de poder distintos? Antes, no século XIX, provavelmente comandadas por dois senhores de terras e políticos que, para marcar seus territórios, erigiram suas residências às margens dessas praças. Praças inseridas na lógica do capital, e com resquícios do passado constitutivo da cidade, a exemplo da presença material dessas residências, mesmo reutilizadas figuram como marcas de ocupação, de definição pretérita, e ainda atual, de territórios. Para discutir a questão, discussões preliminares, entender Teresina na totalidade das relações envolvidas na produção de seu espaço: "tentar captar a formação de uma sociedade abordada a partir de seu território" (Moraes, 2001: 105).

Teresina é fundada em 1852, como parte das inovações do Conselheiro José Antônio Saraiva, então Presidente da Província do Piauí, que transferiu para a nova capital o poder administrativo da antiga capital Oeiras ${ }^{5}$, às margens do rio Parnaíba. Uma ação em consonância com um ideal preconizado nas capitais europeias, que abrangia as discussões sobre a importância de planejar as cidades, de propor mudanças modernas como Teresina, que é considerada a primeira cidade-capital planejada e construída do Império brasileiro (Braz e Silva, 2012) ${ }^{6}$.

Menezes (2001: 10), ao prefaciar Cidades Capitais do Século XIX, apresenta a necessidade de, junto com as ideias consolidadas de revolução no século XIX, o desejo dos Estados de reorganizar seus territórios: "planejar a cidade (especialmente a cidade capital), assim, é tanto planejar o território, quanto planejar a sociedade". Teresina podia ser inserida como extensão, independente de sua distância escalar, da mundialização de

\footnotetext{
${ }^{5}$ Antes mesmo dessa transferência da capital, havia uma discussão de transferir a Vila do Poti (como era denominada anteriormente Teresina) para a Chapada do Corisco, onde atualmente está localizada parte da área central de Teresina.

6 Não serão discutidas aqui, as razões de sua transferência, conteúdo amplamente discutido na historiografia piauiense, que inclui a centralidade de localização do novo local para diminuir a importância econômica da cidade maranhense de Caxias. Sobre influências, polêmicas e hipóteses na configuração da cidade de Teresina, e possíveis razões de sua transferência ver: Silva Filho, 2007 e Braz e Silva, 2012; Gandara, 2011.
} 
projetos modernos para as capitais no século XIX, mesmo que em termos de representação.

Um dado considerado por Salgueiro (2001: 141) acerca da produção do espaço de Belo Horizonte: "a ausência, no Brasil do século XIX, de um discurso sistemático sobre o território e a cidade não significa que as questões do debate internacional deixassem de estar presentes". E a materialização desse discurso, ainda que não atingisse a totalidade desejada, projetou-se em aplicações na organização das cidades, nas soluções empregadas: "aumentar a mobilidade, obedecer ao máximo as ligações funcionais, respeitar o equilíbrio da centralidade para fazê-la funcionar melhor" (Lepetit, 2001: 60).

Como exemplo dessa ligação funcional, as praças visitadas estão separadas/conectadas por ruas, a cerca de setecentos metros uma da outra, e estão encravadas em área central, eixo preponderante no traçado primevo da cidade, próximas à margem do Rio Parnaíba (Figura 1).

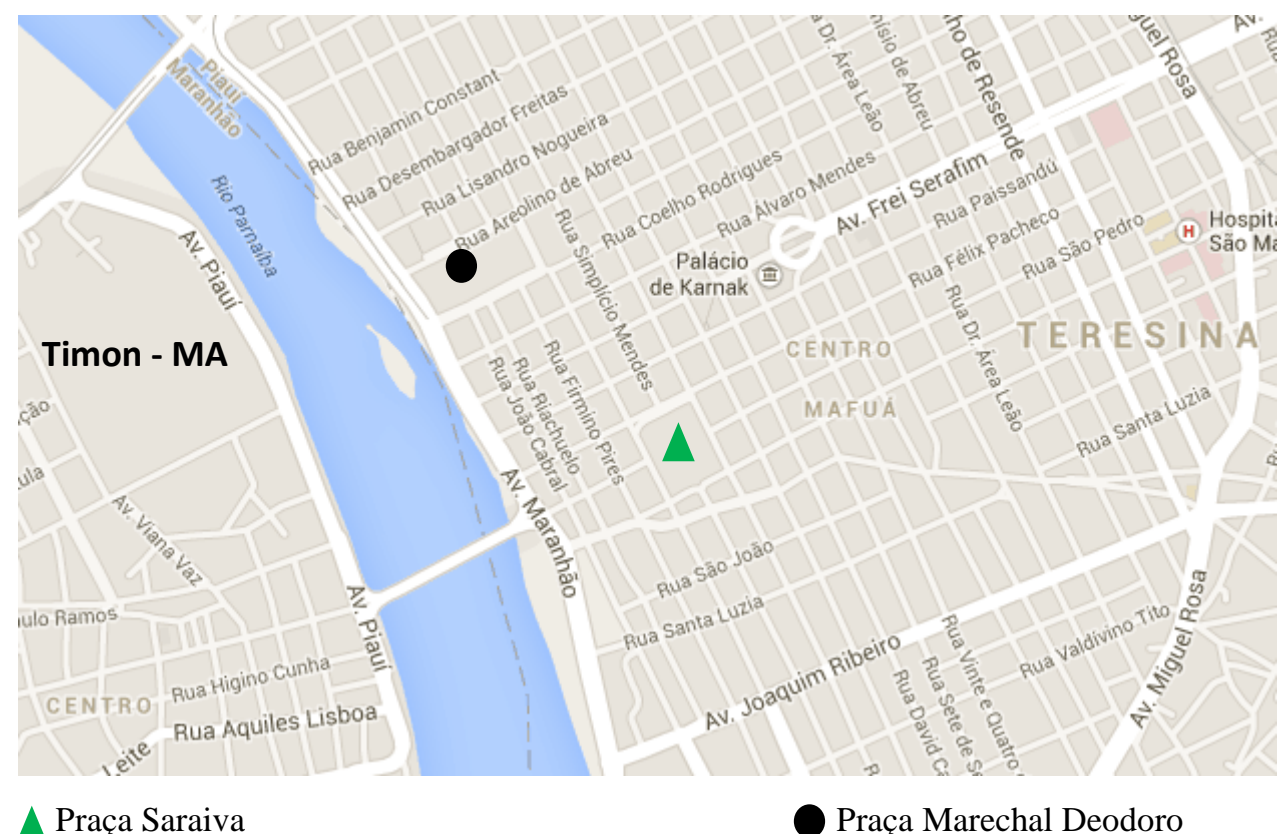

Figura 1 - Localização das Praças. Fonte: Google Maps, 2013 (com legendas adaptadas)

O arranjo das praças em torno de edifícios públicos (Lepetit, 2001) é outra marca da organização espacial da modernidade.

A Praça Marechal Deodoro, ou Praça da Bandeira, como é mais conhecida, guarda, em seu entorno, marcas dessa organização construída logo após a mudança: Mercado Público, Igreja Matriz Nossa Senhora do Amparo, e outras edificações do 
período, mas que passaram por reutilizações, como o Museu do Piauí - Casa de Odilon Nunes. Originalmente residência, depois Palácio do Governo, Tribunal de Justiça do Estado e, por último, em 1980, museu. A casa pertenceu à família do Comendador Jacob Manoel Almendra, português de origem, e proprietário de terras no interior do Piauí, que, na capital, teria recebido a maioria dos terrenos da parte Norte da referida Praça (Museu, 2013).

A Praça Conselheiro Saraiva contém a Catedral de Nossa Senhora das Dores, de $1871^{7}$, colégio de ordem religiosa, e a Casa da Cultura de Teresina, a outra marca territorial que, também como o Museu na outra Praça, passou por alguns usos desde a sua construção inicial de residência:

A Casa da Cultura de Teresina, inaugurada em 12 de agosto de 1994, ocupa uma edificação construída entre 1870 e 1880, pelo Sr. João do Rego Monteiro, o Barão de Gurgueia (1809-1897), para sua residência e família. Segundo historiadores, além de residência, a casa serviu também como quartel e enfermaria. Entre 1906 e 1911, o Monsenhor Joaquim d'Almeida instalou um Seminário no prédio e, em 1913, os herdeiros do Barão venderam o prédio para a Diocese de Teresina, que deu continuidade ao Seminário. Depois de fechado, o casarão foi transformado em residência episcopal, tendo sofrido algumas alterações na fachada principal (...). Com a transferência do Seminário para outro local, nele passou a funcionar, por vários anos, a sede do Departamento Nacional de Obras Contra as Secas (DNOCS) no Piauí, para depois abrigar, também por longo período, o Colégio Pedro II, que fez diversas modificações no prédio. Em 1986, foi tombado pelo Departamento do Patrimônio Histórico, Artístico e Natural do Piauí. O prédio é um dos mais bonitos exemplares da arquitetura eclética piauiense da segunda metade do século XIX, com aplicação das tradicionais ogivas nas portas e janelas. Em 1993, iniciaram-se as obras de restauro do prédio através de convenio firmado entre a Prefeitura de Teresina e o Governo do Estado do Piauí. O pavimento superior foi cedido, pelo prazo de vinte anos em forma de comodato, pela Arquidiocese de Teresina à Prefeitura, que alugou o pavimento térreo para complementar a ocupação do edifício. Assim, em 1994, após restaurada, foi inaugurada a Casa da Cultura de Teresina no imponente casarão da Praça Saraiva, pelo Governador Guilherme Melo e Prefeito Wall Ferraz (Iglesias, 2010: 45-46).

Entre as marcas de formação territorial, essas duas Casas, hoje instituições culturais, possuíam no século XIX representação de dois grandes proprietários de terras e políticos que, provavelmente, imprimiram seu poder na dinâmica do espaço urbano da capital no século XIX. Com feições arquitetônicas distintas, as duas casas representam pontes entre tempos, marcos territoriais. A casa do Barão com reminiscências rurais em sua estrutura, e a casa dos Almendras, casarão de estilo eclético composto por dois pavimentos, ao gosto das casas urbanas do Império. Dois senhores, dois proprietários,

\footnotetext{
${ }^{7}$ Construída às expensas do Barão de Gurgueia, político e fazendeiro, natural de Estanhado, atual União, Piauí.
} 
dois territórios envoltos nas praças (Figuras 2 e 3), acrescentados à dinâmica de diversas classes sociais em torno dessas estruturas.

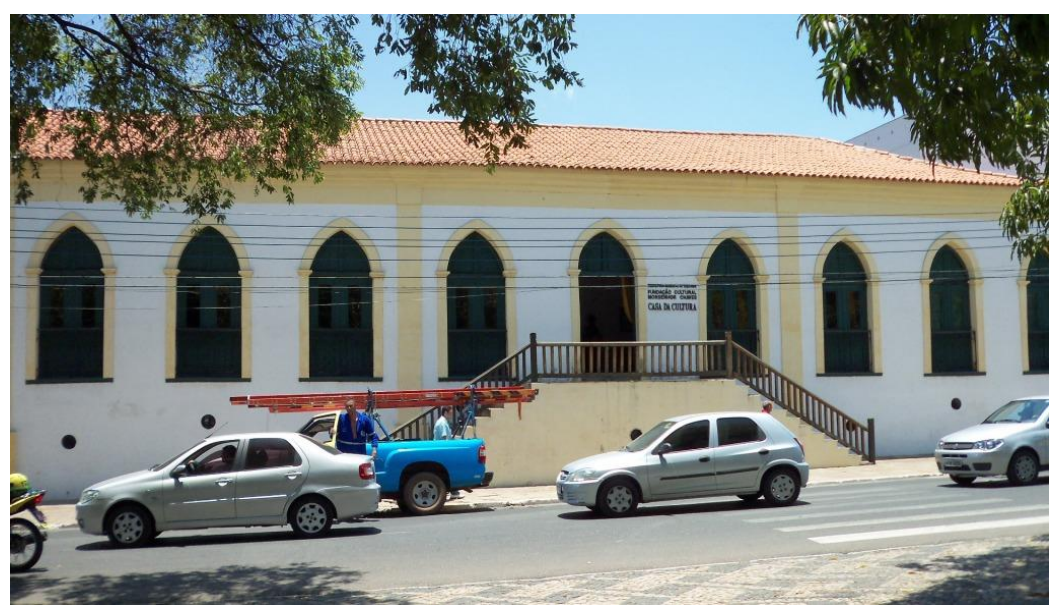

Figura 2 - Fachada da Casa da Cultura. Fonte: Rosângela Barros, 2011.

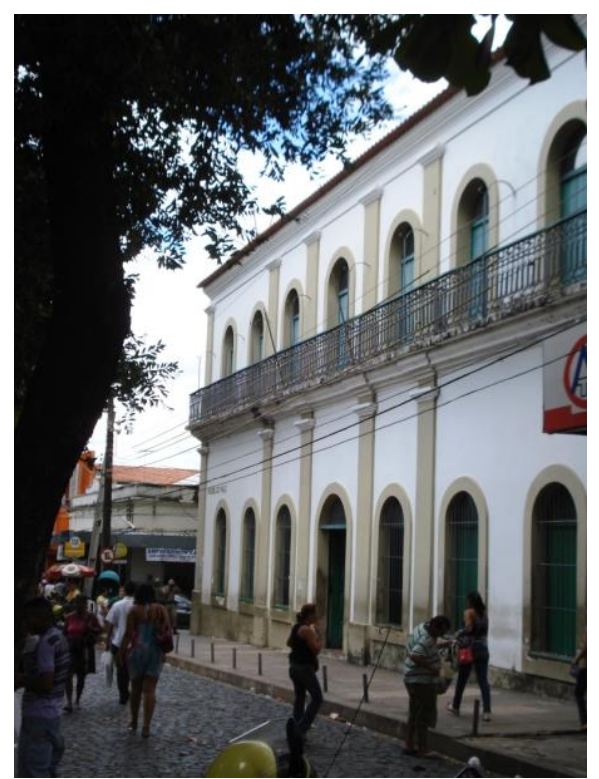

Figura 3 - Fachada do Museu do Piauí. Fonte: Fabrícia Santos, 2011

A lógica desigual da produção do espaço em Teresina "acolheu" essas casas e as praças em seu processo, porém, os processos territoriais ao longo do tempo não são os mesmos. As funções das praças, diferente das casas, permanecem em vários usos, mas os diferentes sujeitos históricos que as produzem alteram, ao longo do tempo, o processo de valorização do espaço. Este cenário seria um esboço para o entendimento das praças como territórios, com relações de poder as mais diversas que formaram algumas imagens ${ }^{8}$ para essas praças.

\section{Imagens das praças - distanciamento, estigmas criados}

Apesar das imagens construtivas associadas às praças, outras imagens também possuem extrema força de representação, de forma que contemplar as duas praças como parte do conteúdo de Arqueologia Histórica visou romper alguns desafios. Entre eles o distanciamento que os discentes possuíam dessas referências patrimoniais, provocado pela situação de instabilidade à segurança devida à ameaça de furtos e outras formas de

\footnotetext{
${ }^{8}$ Como exemplo ver: Tito, 2012.
} 
violência que se tornaram características nos centros urbanos brasileiros. Muitos desses centros têm seus espaços segregados, um efeito provocado, sobremodo, pelo esvaziamento dos domicílios e de alguns estabelecimentos comerciais, como também a valorização de outras áreas das cidades (Smith, 2007).

Funari (2005: 5) observa a importância da Arqueologia Histórica "engajada e pública para resgatar vozes, direitos de parcelas não hegemônicas" na formação territorial brasileira. As praças visitadas, figuram como estruturas resultantes de determinações de uma elite que centralizou a decisão de suas construções e possíveis permanências, como lugares de controle da população, todavia, essa mesma população produz sentidos singulares para essas construções e outras referências patrimoniais, apesar dos estigmas criados para esses locais. Fato analisado por Bakhtin (2008), quando considera as praças europeias na Idade Média como portadoras de uma significação própria consolidada por seus frequentadores, independente da ordem vigente.

A fim de principiar uma superação de uma imagem distanciada para as praças, foi proposto olhar esses espaços como parte da história e da memória da cidade, gerar discussões sobre a possibilidade de reconhecê-los [ou não] como seus, e concebê-los como portadores de cultura material e imaterial passíveis de estudo arqueológico, como parte da produção do espaço na paisagem urbana de Teresina. Além de poder contribuir com diminuição da invisibilidade desses locais.

\section{Procedimentos: aulas nas praças}

Para embasar a atividade, as praças visitadas foram discutidas como territórios, locais de tensões, de conflitos, com temporalidades distintas: umas alteradas ao longo de décadas, ou ao longo do dia, como micro territórios determinados por quem as ocupa ao sabor dos diferentes horários, como é o caso da Praça da Bandeira, onde na mesma área, e ao mesmo tempo, misturam-se: árvores, monumentos, vendedores ambulantes dos mais diversos artigos, pessoas sem moradia ${ }^{9}$, artistas mambembes, transeuntes de várias procedências e destinos, bancos com bases zoomorfas, pombal, locais de parada para transporte público, pontos de prostituição, entre outros elementos (Figura 4). A Praça Saraiva tem seus espaços mais vazios durante o dia (Figura 5), mas também

\footnotetext{
${ }^{9}$ Em situação de rua.
} 
comporta características semelhantes à da Bandeira, como os pontos de espera de transporte, alamedas com árvores, e à noite, no seu entorno, pontos de prostituição feminina e masculina.

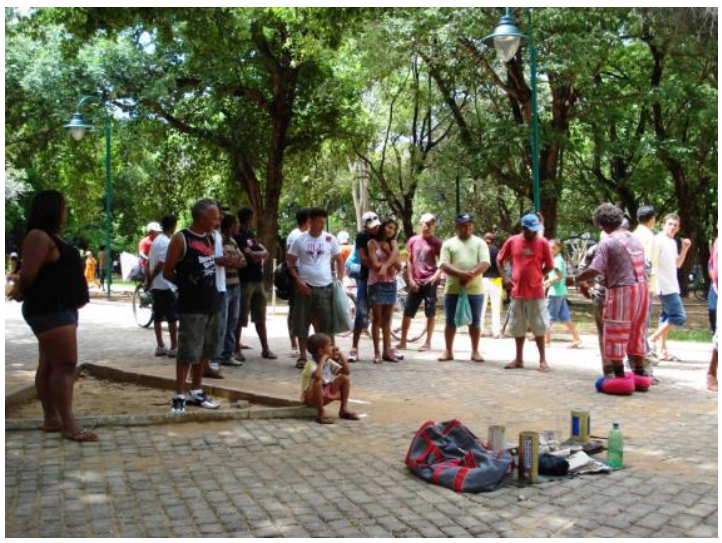

Figura 4 - Exemplo de movimento na Praça da Bandeira. Apresentação de artista mambembe. Fonte: Fabrícia Santos, 2010

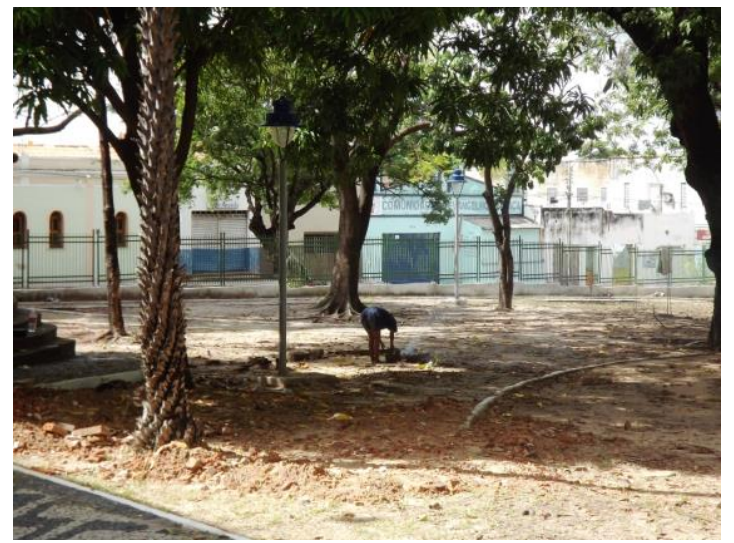

Figura 5 - Imagem de aspectos da Praça Saraiva no meio da manhã. Fonte: Fabrícia Santos, 2011

Como resultado da inclusão de visitas a estes locais constatou-se a contribuição social da Arqueologia ao proporcionar meios de desvelar distintas realidades patrimoniais. Aproximações com as propostas da Arqueologia Pública no sentido em que: "a Arqueologia pode desempenhar um papel significativo mostrando a diversidade, evidenciando a pobreza no passado, celebrando a arquitetura comum, fortificações que são comuns em vez das geralmente valorizadas" (Funari; Oliveira; Tamanini, 2005: 106).

A partir dessa perspectiva, o espaço dessas praças foi compreendido como aglutinador de vivências extremamente importantes para uma leitura das tramas que formam o tecido urbano do Centro de Teresina. As praças são vitais ao funcionamento do Centro, apesar de serem preteridas aos atuais centros de lazer e compras como os Shoppings Centers. No entanto, elas guardam sobre o solo, e talvez entre o solo, marcas elucidativas sobre a ocupação humana da cidade e, possivelmente, de outros momentos além da denominação de cidade atribuída a partir do século XIX.

A prática de visitas orientadas em cidades, como possibilidade de educação para o patrimônio, vem sendo desenvolvida como uma das formas de (re)conhecimento de referências culturais (Magnani, 2007; Abreu, 2011), como uma proposta de realizar uma leitura da paisagem urbana, para entender suas tessituras, às vezes extremamente 
fluídas, fixadas entre as memórias dos que transitam e utilizam as praças, e/ou materializadas nas estruturas edificadas, projetadas, ou em possíveis fragmentos compactados entre o solo.

Para execução das aulas foram estruturados dois roteiros discutidos com os discentes: o da Praça da Bandeira no segundo período de 2010 ${ }^{10}$; e o da Praça Saraiva, no segundo período de 2011. Os trajetos tiveram a duração de cerca de quatro horas cada, e incluíram também visitas ao Museu do Piauí e à Casa da Cultura, respectivamente. Como forma avaliativa, sobre o conteúdo explorado nas aulas, a apresentação de propostas de pesquisa arqueológica sobre essas áreas e seu entorno por parte dos discentes.

Durante as visitas foram realizadas paradas em pontos sugeridos nos roteiros com observação e discussão do que era identificado (Figuras 6 e 7), e as observações além do roteiro $^{11}$. O contato com transeuntes em algumas circunstâncias, que paravam para ouvir, na maioria das vezes por curiosidade, e com pessoas que trabalham nas proximidades, como vendedores no Mercado Público, em frente à Praça da Bandeira, possibilitou ouvir relatos de memórias associadas aos diversos momentos na Praça: local de espera de quem desembarcava ou embarcava no rio Parnaíba, de namoro, de festividades, de trabalho, de conflitos.

\footnotetext{
${ }^{10}$ A atividade também foi realizada durante a recepção de novos alunos no curso, no primeiro semestre de 2012.

${ }^{11} \mathrm{Na}$ primeira visita, ao final, alguns alunos demandaram a observação de fachadas de antigas residências fora do eixo da Praça da Bandeira, algumas em processo de alteração e destruição. O que permitiu constatar algumas predominâncias de estilos arquitetônicos no Centro: como o Art Decó e o Neoclassicismo, estilo último que rendeu proposta de tema para uma das atividades na disciplina Arqueologia II entre 2011 e 2012, com conteúdo voltado para a Arqueologia Clássica, na qual os discentes identificaram a influência greco-romana, por meio do neoclassicismo em fachadas contemporâneas. Sobre os estilos arquitetônicos em Teresina, ver: Melo (2002).
} 


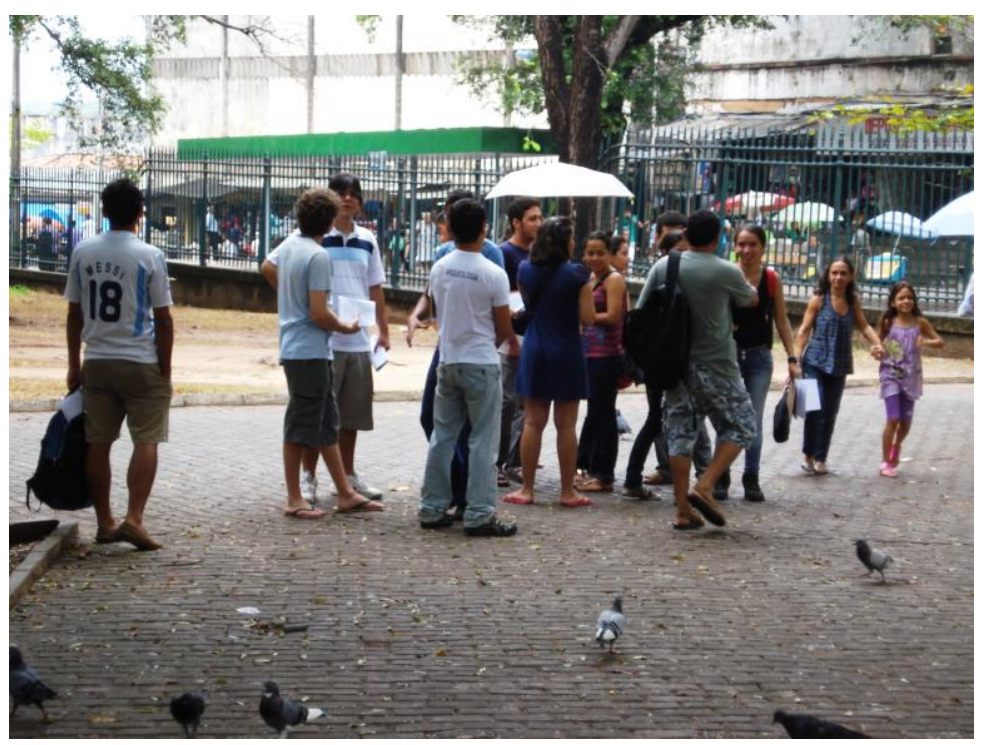

Figura 6 - Aula na Praça da Bandeira. Fonte: Fabrícia Santos, 2010

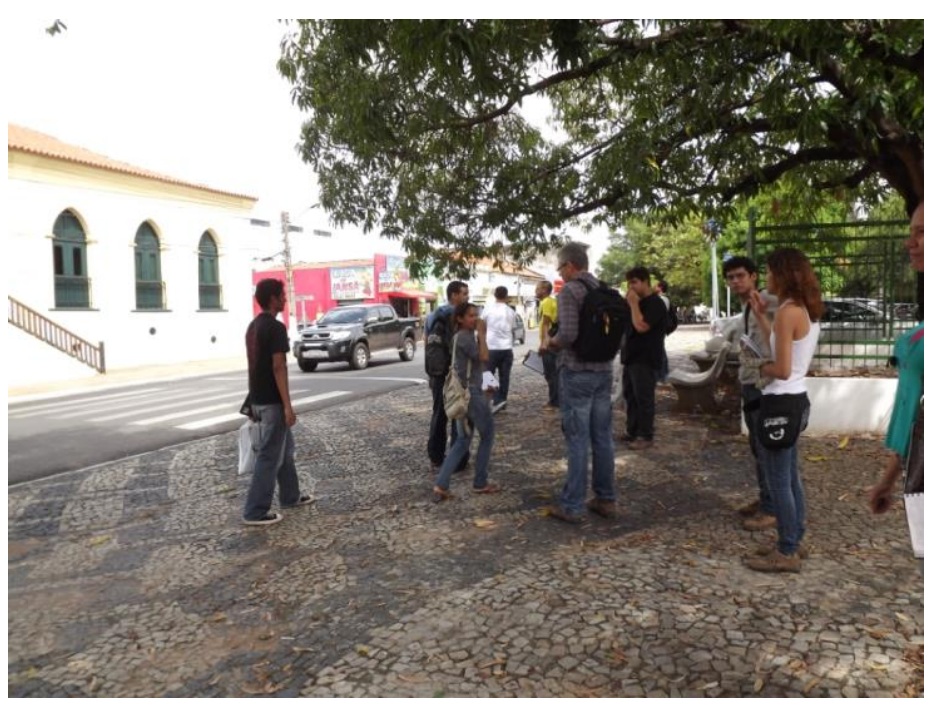

Figura 7 - Observação da Casa da Cultura a partir da Praça Saraiva. Fonte: Fabrícia Santos, 2011

\section{Os roteiros}

Os roteiros foram elaborados a partir de visitas prévias ${ }^{12}$ aos locais, de uma revisão da literatura sobre essas praças e demais referências patrimoniais associadas a elas, e diálogos com os discentes em sala e nas praças, a fim de apontar para uma análise preliminar de possíveis questões para pesquisa arqueológica em áreas urbanas.

Entre os conteúdos explorados nas visitas: referências patrimoniais materiais e imateriais observadas por meio de memórias, de histórias impressas, e entre pessoas, na toponímia e traçados das ruas e demais logradouros, nas edificações e nos acervos dos museus, nas fachadas das diversas construções, nos sons, nas cores, nos odores, nas texturas das referências patrimoniais, entre as pessoas nos seus trajetos e pontos de parada.

Os roteiros utilizados seguiram as seguintes propostas: o primeiro, Desvelar mobilidades do tempo no centro de Teresina: um olhar sobre a Praça da Bandeira (executado no período de 2010 2) foi composto de texto introdutório com a seguinte análise preliminar (Santos, 2010):

\footnotetext{
${ }^{12}$ Realizadas pela docente da disciplina.
} 
[Texto] Largo do Amparo, Praça da Constituição, Praça da Bandeira, Praça Marechal Deodoro da Fonseca são denominações que identificam, a partir da segunda metade do século XIX, um logradouro em Teresina, no Piauí (Ârea Leão, 2006; Abreu; Lima, 2000; Brito et al., 2010).

As praças, parques, passeios públicos configuram-se como marcos de referência de memória e de história na vida dos habitantes das cidades, e entre aqueles que estejam de passagem. Memória e história permeadas por afetividades, conflitos, trabalho, lazer, celebrações a partir de um espaço que comporta territórios de diversos ocupantes da/na praça, que a produzem sob o signo contraditório do espaço público na mobilidade do tempo histórico.

Esses espaços possuem usos diferenciados pela população ao longo do tempo, o que implica uma alternância entre períodos de enobrecimento e/ou esquecimento dos mesmos, assim, o desafio: como ler/ver uma praça nessa mobilidade?

A Praça da Bandeira (nomeação mais recorrente) comporta elementos que poderiam ser atributos de um jardim histórico (Delphim, 2005; Silva, 2010): árvores, alamedas, gradil, pombal, bancos, monumentos, estátuas, entre outros. A Praça é considerada uma marca na paisagem de Teresina, não no sentido de uma paisagem imóvel, mas como se fosse um palimpsesto (Cosgrove; Daniels, 2000), um texto com várias inscrições, umas aparentes, outras apagadas ou reescritas ao sabor das contradições das sociedades que a produz.

O objetivo da visita é propor um "exercício do olhar para ver" (Goodey, 2002) a cidade de Teresina a partir da Praça da Bandeira, inseri-la na totalidade da produção da cidade como materialização das projeções da sociedade (Lefebvre, 1973), a fim de provocar entre os discentes da disciplina Arqueologia Histórica, do Curso de Arqueologia e Conservação de Arte Rupestre (UFPI), reflexões sobre as possibilidades de pesquisa (Praça..., 2007; Toccheto; Thiessen, 2010) nesta área ao contemplar possíveis fontes de informação e temas relacionados aos conteúdos explorados em sala, de forma a compor, em seus relatórios, propostas de estudos arqueológicos a partir da visita.

A praça é um sítio histórico? Um jardim histórico? Um "não-lugar" (Augé, 2004)? Um cartão postal? Há uma “estratigrafia do esquecimento" (Bruno, 1999), uma invisibilidade urbana?

Além do texto acima, uma sequência de pontos a serem observados, o uso de uma imagem fotográfica panorâmica do início do século XX, e mapa da área que comporta a praça e ruas de seu entorno.

O segundo roteiro, aplicado no segundo semestre de 2011: Desvelar mobilidades do tempo no centro de Teresina: um olhar entre a praça Saraiva e a Casa da Cultura, também seguiu a mesma estrutura do anterior, com texto e pontos de observação (Santos, 2011):

Conferir novas funções às construções e aos lugares implica um movimento no/do tempo que pode causar esquecimentos - vazios de memórias que, rapidamente, podem ficar perdidas em meio às mudanças rápidas das necessidades urbanas. Esta é uma das sensações que o espaço urbano provoca - perder-se nas mudanças! Não conseguir deter as alterações na paisagem, sem que fiquem, devidamente registradas, para que se tenha acesso a um entendimento sobre a contradição entre a permanente construção e destruição de estruturas e sociabilidades entre tempos.

As mudanças são resultantes da produção do espaço (Harvey, 2005), provocam esquecimentos e lembranças (Rossi, 2010), presentes nas marcas na paisagem: ruínas, construções inteiras, traçados de caminhos, toponímias. Algumas marcas, apesar de visíveis, muitas vezes passam invisíveis ao olhar. Para superar uma aparente "cegueira", e entender os vácuos de memórias, a prática de um exercício 
necessário ao campo de interpretação do patrimônio cultural, seja urbano, seja rural olhar para ver. E como ver? Muitas das marcas materiais na paisagem estão visíveis, outras, em brumas, ou entre o solo. Logo, uma observação inicial é medida essencial, preventiva, a fim de evitar equívocos: parar, olhar, ver, fotografar, questionar as marcas na produção do espaço, conhecer as formas, ver o fluir do cotidiano, saber o que se diz/disse sobre o que se observa.

Para um "exercício do olhar" (Goodey, 2002), a escolha de um recorte: uma praça e seu entorno, mas, sem perder o vínculo de sua inserção na paisagem urbana, ao considerar as praças como aglutinadoras de referências patrimoniais nas/das cidades. Assim, a presente atividade tem como objetivo realizar uma visita a uma pequena parte da cidade de Teresina, à praça Saraiva e à Casa da Cultura (Iglesias, 2010) e seu entorno, partindo da ideia de ver esses locais sob uma perspectiva da Arqueologia Histórica (Orser, 2000), como marcas materiais que podem possibilitar questionamentos e possíveis entendimentos sobre a produção do espaço dessa cidade a partir da interpretação arqueológica.

A lógica de visitação vinculou: observação da praça, visita à Igreja Nossa Senhora das Dores, e observação de outras dinâmicas associadas: a presença de colégio de ordem religiosa, estabelecimentos comerciais; áreas de prostituição; paradas de transporte público, tipos de comércio. Em seguida, visita à Casa da Cultura, e momentos de diálogo sobre o que era observado.

\section{Resultados e possibilidades}

Além de relatórios, com propostas de pesquisa dos discentes, ficaram outras impressões positivas, como certa diminuição, entre eles, do receio de ir ao Centro de Teresina, e a importância do aprender a ver o patrimônio cultural local, mesmo entre os que passam com certa frequência nas praças, ou em outros lugares no Centro, e que sabem de sua existência, mas evitavam por medo da violência.

A inclusão de conteúdos locais na prática pedagógica no ensino de Arqueologia Histórica é um procedimento a ser considerado. Os "fragmentos" tratados por esta disciplina também são referências culturais que não estão desvencilhadas da totalidade da produção do espaço geográfico sob o capitalismo (Harvey, 2005). Uma produção que influi diretamente na ausência (destruição) e presença (permanências) de referências patrimoniais no movimento do capital em seu desenvolvimento desigual e combinado. Talvez, por serem consideradas referências "novas" e "comuns" podem conter uma fragilidade de preservação bem maior frente às referências "antigas".

A aproximação dos discentes com o seu patrimônio, com as imagens reais da cidade, pode contribuir na ampliação das perspectivas de preservação. Um retorno constante ao patrimônio local que enfrenta, a partir das demandas do capitalismo, sérios 
riscos, e talvez, o mais drástico deles, o não reconhecimento da população que olha, mas não o vê em sua dimensão de portador de vidas, de memórias, de histórias.

Se não há preocupação mínima com o patrimônio ainda visível, a atenção com a cultura material a ser identificada em escavações de sítios arqueológicos nessas áreas pode ser negligenciada. Não significa afirmar a importância do "visível" em detrimento de um "invisível" entre o solo, mas a necessidade de conciliar ações mútuas de integração da importância das referências culturais de forma interativa e não excludente. Não se trata de propor ações generalistas, mas sugerir discussões reiteradas sobre as ações de reconhecimento patrimonial que, nos cursos que tratam diretamente da questão, como os de Arqueologia, devem abordar de forma assídua e comprometida em propor e desenvolver ações continuadas de educação para/com o patrimônio. O que parece tolo, conhecer sua própria cidade, é medida urgente de estabelecer significações, elos, para que se possa olhar e ver, a fim de obter a dimensão sempre viva, real, da relação entre tempos, uma intenção extremamente almejada nos estudos com o passado (Marcén; Gurina, 1998; Albuquerque Júnior, 2012).

Entre os resultados, além de ações educativas para/com o patrimônio local, uma das propostas de pesquisa apresentada, foi transformada em trabalho de conclusão de curso de Paiva (2011): O passado que anseia virar presente: o (re)conhecimento da praça da Bandeira como sítio histórico da cidade de Teresina. Monografia que discute a organização do espaço teresinense a partir da Praça da Bandeira, aponta para as tramas entre tempos de produção do espaço urbano, e indica as possibilidades de intervenção arqueológica no local.

Como foi mencionado, as praças, assim como outras referências culturais nas cidades, são como palimpsestos. Ler essas paisagens marcadas, remarcadas carece exercício. Exercícios de reflexão teórica e ação prática, nos quais é possível inserir a educação como práxis, não como mera atividade, mas como ação de transformação (Pimenta, 2006). Ação em que as pessoas possam ter a possibilidade de aprender a ver, e poder discutir sobre as referências patrimoniais que as representam, institucionalizadas, ou não.

$\mathrm{Na}$ difícil empreitada entre lembrar e esquecer, neste caso referências culturais, Rossi (2010: 89) acentua que "só se pode conservar aquilo que, uma vez encontrado, foi considerado digno de conservação", logo, o problema maior para as políticas de salvaguarda pode ser a falta de possibilidades contínuas, entre os vários segmentos da sociedade, para analisar, discutir, decidir sobre o porquê do que é olvidado ou lembrado. 
No interior dessa reflexão, que parece óbvia, aulas, oficinas, palestras, e pesquisas continuadas entre professores, alunos, e a comunidade em geral, figuram como momentos fecundos para discussões e produção de conhecimento, sobretudo no campo patrimonial. Mediações entre tempos, onde ainda é possível ver, de perto, as reações, as impressões reais entre os participantes sobre suas referências patrimoniais, e construir propostas efetivas de preservação.

\section{Referências}

ABREU, Irlane G. de; LIMA, Iracilde Maria de M. F. Igreja do Amparo: o marco zero de Teresina. Cadernos de Teresina. Ano XII, n. 33, out., p. 20-25, 2000.

ABREU, Maurício. Sobre a memória das cidades. In: CARLOS, Ana Fani A.; SOUZA, Marcelo Lopes de; SPOSITO, Maria Encarnação Beltrão (orgs.). A produção do espaço urbano: agentes e processos, escalas e desafios. São Paulo: Contexto, 2011. p. 19-39.

ALBUQUERQUE JÚNIOR, Durval Muniz de. Fazer defeitos nas memórias: para que servem o ensino e a escrita da história. In: GONÇALVES, Márcia de Almeida [et al.] (orgs.). Qual o valor da história hoje? Rio de Janeiro: Editora FGV, 2012.

ÂREA LEÃO, José Elias. Memória Fotográfica. Praça da Bandeira e suas Lembranças. Revista Presença. Teresina. Ano XXI, n. 35. 1o. Sem., p. 22-29, 2006.

AUGÉ, Marc. Não-lugares: introdução a uma antropologia da supermodernidade. 4.ed. São Paulo: Papirus, 2004.

BAKHTIN, Mikhail. A cultura popular na Idade Média e no Renascimento: o contexto de François Rabelais. 6. ed. Tradução de Yara Frateschi Vieira. São Paulo: Editora Universidade de Brasília, 2008.

BARROS, Rosângela Dantas. Figura 2 - Fachada da Casa da Cultura. Fotografia. Outubro, 2011.

BRAZ E SILVA, Angela Martins Napoleão. Planejamento e fundação da primeira cidade no Brasil Império. Cadernos do PROARQ Rio de Janeiro. UFRJ, FAU, Programa de PósGraduação em Arquitetura, n. 18, p. 216-236, jul., 2012.

BRITO, Hiana; RIBEIRO, Joselivalto; ALVES, Verônica; BRITO, Jacqueline. Estudo da funcionalidade das praças Pedro II, Rio Branco e Marechal Deodoro da Fonseca na cidade de Teresina, Piauí. Congresso de Pesquisa e Inovação da Rede Norte Nordeste de Educação Tecnológica João Pessoa, PB, 2007. Disponível em: www.redenet.edu.br/../20080212_082642_LAZE-005.pdf Acesso em: 10/09/2010. 
BRUNO, Maria Cristina O. A importância dos processos museológicos para a preservação do patrimônio. Revista do MAE. n. 3. São Paulo: Edusp, 1999. p. 333-337.

COSGROVE, Denis; DANIELS, Stephen. The iconography of landscape. Essays on the symbolic representation, design and use of past environments. NY. Cambridge University Press, 2000.

DELPHIM, Carlos Fernando de Moura. Intervenções em Jardins Históricos: manual. Brasília: IPHAN, 2005.

FERRARA, Lucrécia D’Allesio. As máscaras da cidade. Revista USP. São Paulo. Abr., maio, p. 3-10, 1990.

FUNARI, Pedro Paulo A. Teoria e métodos na Arqueologia contemporânea: o contexto da Arqueologia Histórica. Mneme Revista de Humanidades. Dossiê Arqueologias Brasileiras, v. 6, n. 13, p. 1-5, dez. 2004/jan. 2005.

FUNARI, Pedro Paulo A.; OLIVEIRA, Nanci V.; TAMANINI, Elizabete. Arqueologia para o público leigo no Brasil. In: FUNARI, Pedro Paulo A.; ORSER JR, Orser; SCHIAVETTO, Solange Nunes de O. (orgs.). Identidades, discurso e poder: estudos de arqueologia contemporânea, 2005. p. 105-116.

GANDARA, Gercinair Silvério. Teresina: a Capital sonhada do Brasil Oitocentista. História. São Paulo. v. 30, n.1, p. 90-113, jan./jun., 2011.

GINZBURG, Carlo. Olhos de madeira: nove reflexões sobre a distância. Tradução de Eduardo Brandão. São Paulo: Companhia das Letras, 2001.

GOODEY, B. Olhar múltiplo na interpretação de lugares. In: MURTA, Stela Maris; ALBANO, Celina. (orgs.). Interpretar o patrimônio: um exercício do olhar. Belo Horizonte: Ed. da UFMG, 2002. p. 75-94.

GOOGLE Maps. Figura 1 - Localização das Praças. Disponível em: https://maps.google.com.br/maps/mm. Acesso em 23/01/2014.

HARVEY, David. A produção capitalista do espaço. Tradução de Carlos Szlak. São Paulo: Annablume, 2005.

IGLESIAS, Diego. Casa da Cultura: de "Casa do Barão" a Centro Multicultural. Revista Presença. Teresina. Ano XXV, n. 45. p. 44-46, 2010.

LEFEBVRE, Henri. De lo rural a lo urbano. Barcelona: Ediciones Peninsula, 1973.

LEPETIT, Bernard. Das capitais às praças centrais. Mobilidade e centralidade no pensamento econômico francês. In: SALGUEIRO, Heliana Angotti (org.). Cidades Capitais do Século XIX: racionalidade, cosmopolitismo e transferência de modelos. São Paulo: Editora da Universidade de São Paulo, 2001. p. 41-63.

MAGNANI, José Guilherme C. Santana de Parnaíba: memória e cotidiano. In: ABREU, Regina; CHAGAS, Mário de S.; SANTOS, Myrian Sepúlveda dos (orgs.). Museus, coleções e patrimônios. Rio de Janeiro: Garamond, MinC/IPHAN/DEMU, 2007. p. 283-323. 
MARCÉN, Paloma G; GURINA, Marina P. El tiempo em Arqueología. Madrid: Arco/Libros, 1998.

MELO, Alcília Afonso de Albuquerque e. Arquitetura em Teresina: 150 anos; da origem à contemporaneidade. Teresina: Halley, S/A Gráfica e Editora, 2002.

MENEZES, Ulpiano B. de. Prefácio: Cidade Capital, Hoje? In: SALGUEIRO, Heliana Angotti (org.). Cidades Capitais do Século XIX: racionalidade, cosmopolitismo e transferência de modelos. São Paulo: Editora da Universidade de São Paulo, 2001. p. 9-17.

MORAES, Antonio Carlos Robert. Bases da formação territorial do Brasil. Geografares. Vitória. n. 2, jun., p. 105-113, 2001.

MUSEU do Piauí Casa de Odilon Nunes. Disponível em: http://www.facesdopiaui.com.br/museu-do-piaui-casa-de-odilon-nunes/ Acesso em 13/05/2013. ORSER JR. Charles E. Introducción a La Arqueología Histórica. Tradução e prólogo Andrés Zarankin. Buenos Aires: Asociación Amigos del Instituto Nacional de Antropología, 2000.

PAIVA, Zafenathy C. de. O passado que anseia virar presente: o (re)conhecimento da praça da Bandeira como sítio histórico da cidade de Teresina. Bacharelado em Arqueologia e Conservação de Arte Rupestre. (Monografia). Teresina. UFPI, 2011.

PIMENTA, Selma Garrido. Práxis - ou a indissociabilidade entre teoria e prática e a atividade docente. In: O estágio na formação de professores. Unidade Teoria e Prática. 7.ed. São Paulo, 2006. p. 81-106.

PRAÇA da Alfândega. Porto Alegre, RS. Brasília: Monumenta, 2007. n. 4. (Coleção Preservação e Desenvolvimento).

RIBEIRO, Rafael W. Paisagem Cultural e Patrimônio. Rio de Janeiro: IPHAN/COPEDOC, 2007.

ROSSI, Paolo. O passado, a memória, o esquecimento. Seis ensaios da historia das ideias. Tradução Nilson Moulin. São Paulo: Editora da UNESP, 2010.

SALGUEIRO, Heliana Angotti. O pensamento francês na fundação de Belo Horizonte: das representações às práticas. In: (org.). Cidades Capitais do Século XIX: racionalidade, cosmopolitismo e transferência de modelos. São Paulo: Editora da Universidade de São Paulo, 2001. p. 135-181.

SANTOS, Fabrícia de Oliveira. Desvelar mobilidades do tempo no centro de Teresina: um olhar sobre a Praça da Bandeira. Texto para roteiro de visita orientada aplicada como atividade na disciplina Arqueologia Histórica (Período 2010 2) do Curso de Bacharelado em Arqueologia e Conservação de Arte Rupestre - UFPI/CCN. Teresina, PI, 2010. (Digitado).

. Desvelar mobilidades do tempo no centro de Teresina: um olhar entre a praça Saraiva e a Casa da Cultura. Texto para roteiro de visita orientada aplicada como atividade na disciplina 
Arqueologia Histórica (Período 2011 2) do Curso de Bacharelado em Arqueologia e Conservação de Arte Rupestre - UFPI/CCN. Teresina, PI, 2011a. (Digitado).

Figuras 3, 4, 5, 6, 7. Fotografias - Praças: Saraiva e da Bandeira. Teresina, 2010-2011.

A produção do espaço piauiense e os caminhos do couro e da carne: leituras para a arqueologia histórica no Piauí (séculos XVIII-XIX). Projeto de Pesquisa. Universidade Federal do Piauí. Edital Programa ICV 2011-2012. 2011b. (Digitado)

SILVA, Aline de Figueirôa. Jardins Históricos do Recife: uma história do paisagismo no Brasil (1872-1937). Recife: CEPE, 2010.

SILVA FILHO, Olavo Pereira da. Carnaúba, Pedra e Barro na Capitania de São José do Piauhy. Belo Horizonte: Ed. do Autor, 2007. V. 3 - Urbanismo.

SILVEIRA, Ana Lúcia R. C. da. A Igreja do Amparo. Teresina, ICF Ed., 2003.

SMITH, Neil. Desenvolvimento desigual: natureza, capital e a produção do espaço. Tradução Eduardo de Almeida Navarro. Rio de Janeiro: Bertrand Brasil, 1984.

Gentrificação, a fronteira e a reestruturação do espaço urbano. Tradução de Daniel de Mello Sanfelici. GEOUSP - Espaço e Tempo. São Paulo, nº 21, p. 15-31, 2007.

TITO, Wenner. PII e Praça Saraiva são a história viva das praças de Teresina. Disponível em: http://www.piaui.pi.gov.br/noticias/index/id/5856. Acesso em 02/01/2012.

TITO FILHO, A. Teresina: ruas, praças e avenidas. Teresina: [s.n.], 1977.

TOCCHETO, F.; THIESSEN, B. A memória fora de nós: a preservação do patrimônio arqueológico em áreas urbanas. In: LIMA, Tânia A. (org.). Revista do Patrimônio Histórico e Artístico Nacional. n. 33, p. 175-199, 2007.

VIDAL, Laurent. Cidades em espera, sociedades em espera no Brasil colonial: alguns desafios metodológicos. In: FRIDMAN, Fania; ABREU, Mauricio (orgs.). Cidades latino-americanas: um debate sobre a formação de núcleos urbanos. Rio de Janeiro: Casa da Palavra, 2010. p. 5361.

Recebido em: 20/09/2014

Aprovado em: 06/11/2014 